\title{
Understanding Stakeholder Synergies Through System Dynamics: Integrating Multi-Sectoral Stakeholder Narratives Into Quantitative Environmental Models
}

OPEN ACCESS

Edited by:

Manel SANSA

France Energies Marines, France

Reviewed by:

Florentin Smarandache, University of New Mexico,

United States SARA TONIOLO,

University of Padua, Italy

*Correspondence: Rachel Gjelsvik Tiller rachel.tiller@sintef.no

Specialty section: This article was submitted to Multi-criteria Decision Making,

a section of the journal

Frontiers in Sustainability

Received: 27 April 2021 Accepted: 19 October 2021 Published: 11 November 2021

Citation:

Tiller RG, Destouni G, Golumbeanu M, Kalantari Z, Kastanidi E, Lazar L,

Lescot J-M, Maneas G, Martínez-López J, Notebaert B, Seifollahi-Aghmiuni S, Timofte $F$, de Vente J, Vernier $F$ and de Kok J-L (2021) Understanding Stakeholder Synergies Through System Dynamics: Integrating Multi-Sectoral Stakeholder

Narratives Into Quantitative

Environmental Models.

Front. Sustain. 2:701180.

doi: 10.3389/frsus.2021.701180

\author{
Rachel Gjelsvik Tiller ${ }^{1 *}$, Georgia Destouni ${ }^{2}$, Mariana Golumbeanu ${ }^{3}$, Zahra Kalantari ${ }^{2}$, \\ Erasmia Kastanidi ${ }^{4}$, Luminita Lazar ${ }^{3}$, Jean-Marie Lescot ${ }^{5}$, Giorgos Maneas ${ }^{2}$, \\ Javier Martínez-López ${ }^{6}$, Bastiaan Notebaert ${ }^{7}$, Samaneh Seifollahi-Aghmiuni ${ }^{2}$, \\ Florin Timofte ${ }^{3}$, Joris de Vente ${ }^{6}$, Francoise Vernier ${ }^{5}$ and Jean-Luc de Kok ${ }^{7}$ \\ ${ }^{1}$ SINTEF Ocean, Trondheim, Norway, ${ }^{2}$ Department of Physical Geography, Stockholm University, Stockholm, Sweden, \\ ${ }^{3}$ National Institute for Marine Research and Development Grigore Antipa (INCDM), Constanta, Romania, ${ }^{4}$ Hellenic Centre for \\ Marine Research (HCMR), Anavyssos, Greece, ${ }^{5}$ Department of Territories, Institut National de recherche pour l'agriculture, \\ l'alimentation et l'environnement (INRAE), Paris, France, ${ }^{6}$ Consejo Superior de Investigaciones Cientificas (CSIC), Madrid, \\ Spain, ${ }^{7}$ Flemish Institute for Technological Research (VITO), Antwerp, Belgium
}

To reach the global aspiration of 17 ambitious SDGs, local realities must be integrated. Often, models are developed based on quantitative statistical data sources from databases on environmental indicators or economics to assess how a given SDG can be achieved. This process however removes the local realities from the equation. How can you best include stakeholders in this mathematical modelling processes distanced from their local realities, though, and ensure higher probability of future compliance with top-down global decisions that may have local consequences once implemented? When researching stakeholder involvement and their ability to form public policy, their opinions often get reported as a single assessment, like counting the fish in the ocean once and stating that as a permanent result. Too seldom do stakeholders get invited back and given the opportunity to validate results and allow researchers to adjust their models based on on-the-ground validation or change requests. We tested the full integration of stakeholders in the modelling process of environmental topics in six different case areas across Europe, with each area holding six sectoral and one inter-sectoral workshops. In these workshops, the scope of the issues relevant to the stakeholders was driven by first the sectoral priorities of the given sector, followed by a merging of issues. In this process, we were able to identify what the commonalities between different sectors were and where synergies lay in terms of governance paths. These results were then returned to the stakeholders in a mixed session where they were able to come with feedback and advice on the results researchers presented, so that the models reflected more closely the perceptions of the regional actors. We present these methods and reflect on the challenges and opportunities of using this deep-integration method to integrate qualitative data from stakeholder inclusion in a quantitative model.

Keywords: sustainable development goals-SDG, stakeholder, conceptual modeling approach, workshops, compliance, qualitative study 


\section{INTRODUCTION}

In 2015, the United Nations General Assembly formulated the 17 sustainable development goals (SDGs) under the 2030 Agenda for Sustainable Development (Kamau et al., 2018). Global aspirations, however, must inevitably meet the realities of stakeholders and policy makers charged with implementing global aspirations. The inclusion of stakeholders and "information gatekeepers ${ }^{1}$ " from the start of any implementation phase is as such arguably critical to achieve the SDGs. The benefits of including the priorities of local agents in a bottom-up approach to governance are multiple. First, by ensuring that local voices are heard, knowledge is exploited, and the process is perceived as more transparent, giving users ownership in decisions that are taken. Local interaction among stakeholders also has an important impact with respect to information sharing and comprehension in decision making (Reed, 2008; De Vente et al., 2016). It promotes, for example, co-creation of knowledge and social learning, including the spread of common understandings of concepts, such as targets and indicators and what this really means on the ground. It also discusses approaches to reaching goals, discussions around the specificities of the sustainability goal in question, as well as challenges and solutions (Smith, 1980; Clark, 1994; Estellie Smith, 1995; Bruckmeier and Höj Larsen, 2008; Leys and Vanclay, 2011). Combined, this can create increased legitimacy and encourage long-term compliance with resultant legislations (Sun, 2017; Coleman et al., 2019).

This development of a broad epistemic community or "community of shared knowledge" (Haas, 1989) that encompasses the key shareholders in a given issue-and geographical area, is key to achieving global aspirations such as the SDGs. Stakeholder integration methods, practices and ideals vary greatly though (Mielke et al., 2017). We argue that the use of an overarching methodology for monitoring a given global challenge at the local level can be beneficial. Generally speaking, developing methods for facilitating comparative analysis between different countries, local communities and socioeconomic regions is important to observing the proceedings toward reaching a global goal-made possible when epistemic communities are activated (Herrera, 2019). Ensuring results are comparable demands an adaptive methodological solution within the context of deep integration of stakeholders and close collaboration of researchers across disciplinary boundaries though. In the context of this article, these interfaces are between coastal and rural areas, mathematical modeling and qualitative perception workshops, and data driven by climatic as well as non-climatic stressors (Cottrell et al., 2018).

In this article, we investigate the interface between qualitative narratives and mathematical modeling to develop a holistic

\footnotetext{
${ }^{1}$ Gatekeepers are “... individuals and groups who collect information regarding the organizations' surroundings, filter it, translate it into the organizations' language and distribute it for use within the organization." The term was first coined by Lewin (1943), and he described it as a metaphorical entrance to a tunnel, via a gate, where the traffic within is controlled by said Gatekeeper, who determines the distribution of information that travels through to reach its destination, Lewin (1943) and Bouhnik and Giat (2015).
}

decision-making support tool. We offer results from a process of performing this kind of cross-sectoral, transdisciplinary and socio-political comparative analysis. Our analysis was driven by a demand from decision makers for predictive tools and evidencebased analysis of the impacts and effectiveness of management alternatives that can address socio-ecological variables. We therefore developed an inter-and transdisciplinary ${ }^{2}$ multimethodological approach of taking qualitative narratives from participatory stakeholder workshops and transforming these into causal loop diagrams and systems for decision support. This is an approach that allows us to address a number of governance questions from global to local and back again, and requires the mix of inter-and intra-disciplinary methods, with a deep integration of representatives from epistemic communities and industry sectors in the given case areas (Brannen, 2005; Elliott, 2005; Kelle, 2006). It's a methodological innovation in that it not only combines qualitative and quantitative methods, but that it does so comparatively-testing it out in six different locations in Europe with diverse inter-and intra-socio-geographical and cultural contexts as well as issue areas, while demonstrating that the method can adapt to different situations while still keeping a comparative element.

We did this within the context of assessing land-sea interactions under different climatic and anthropogenic stressors in six case areas across Europe (Belgium, Greece, Sweden, Romania, Spain and France $)^{3}$. We studied discourse and narratives from 36 sectorial participatory workshop discussions ( ix in each case area). We then developed conceptual maps from each sector and merged these into combined intersectoral causal loop diagrams, capturing the system feedback structures across the sectors. These were then brought back to the stakeholders for feedback and validation in a combined iterative multi-sector workshop. Data from these exercises allowed us to better understand how participants perceive their individual and group roles. It also offered insights into their attitudes, beliefs, and knowledge. This methodological approach may subsequently be one of the methods in the toolbox that can help researchers approach and involve actors in research where results are important for a given decision-making process. Such involvement can ensure more stakeholder legitimacy with the political process, and within the context of this article, results can be translated toward policy advice toward reaching the global aspirations of multiple of the global sustainable development goals.

\section{BLUE-GREEN AND COASTAL-RURAL INTERACTIONS-FROM GLOBAL TO LOCAL}

Current solutions for achieving stakeholder integration are in many cases based on working with them in parallel sectors-both

\footnotetext{
${ }^{2}$ For more in-depth reading on the three most common definitions of integrated studies-multi-, inter-and trans-disciplinary definitions-specifically in the field of sustainability, we recommend reading for example Stock and Burton (2011).

${ }^{3}$ This study was conducted as part of the Horizon 2020 project COASTALhttps://h2020-coastal.eu/.
} 
in terms of aquatic and terrestrial systems. Human beings are however affected by externalities caused by interactions across multiple sectors and ecosystems (Langhans et al., 2019). These interactions affect the lives of people across regions. Globally for example, the rural population has declined as a percentage of the total population from $66 \%$ in 1960 to $44.7 \%$ in 2018 (The World Bank, 2018). This is even lower in the EU, where the rural areas are home of only $29.1 \%$ of the population (Eurostat, 2018). Rural development in the EU faces highly dynamic challenges including global competition, decreasing population densities, lack of employment, aging farm managers and difficulty in taking over farms, desertification, land abandonment, and climate change. These significant challenges were also addressed by the EU Strategic Guidelines for Rural Development (European Commission, 2006). The aim of these guidelines was to improve the competitiveness of the green sector-such as agriculture and forestry-taking into consideration the natural environment, quality of life while simultaneously ensuring a diversity of the rural economy.

At the same time, the coastal areas have had opposite experiences compared to the rural areas, both globally and in the EU. In the former, 2.4 billion people live within $100 \mathrm{~km}(60$ miles) from the coast (United Nations, 2017). In the EU, nearly half the population lives within only $50 \mathrm{~km}$ of the sea. In fact, in 2001 , near $15 \%$ of the entire EU population lived within half a $\mathrm{km}$ from the coast-demonstrating the importance of the blue economy, which employed 4 million people and had a recorded profit of 74.3 billion Euro in 2017 (European Environment Agency, 2016; European Commission, 2019b). The blue economy could potentially contribute to rural development by providing ecosystem goods and services and business opportunities to these areas though. However, blue growth itself also affects coastal ecosystems negatively. This puts them under increasing pressure from a number of industries, including fisheries, aquaculture, energy production, tourism, and shipping. Coastal ecosystems are similarly under pressure from land-based human activities, such as forestry, agriculture and agro-industries. For instance, the current, mainstream agro-environmental policies have failed to effectively lower the nutrient loads below target values from economic activities in rural areas to coastal ecosystems. Consequently, the attainment of good water status defined by the 2015 target laid down in the European Water Framework Directive (WFD) has had to be postponed to 2021, or even 2027 for many watercourses (European Commission, 2019a). Integrated and long-term approaches, as laid out in the EU Common Agricultural Policy, EU Marine Framework Directive and EU Green Deal, and through SDG 14.1 are therefore needed to be implemented at the local scale (United Nations, 2015) to have upstream efficacy at a governance level (Martínez-López et al., 2019a).

Existing research and policy primarily address issues from either a coastal-or rural-based perspectives in isolation, though. This makes it ill-adapted to support effective land-sea integration at the local, regional and macro-regional scale and achieving the related SDGs at the global level. User-friendly instruments for identifying and analyzing challenges and opportunities from an integrated perspective are scarce. It is therefore also difficult to derive effective policy recommendations that are grounded locally from a multi-sectoral perspective. To be effective and accepted, tools for business and policy support need to be based on a participatory, multi-actor approaches. Within the current context, it also needs to include both rural and coastal sectors as well. This will allow us to enhance and exploit co-creation and take into account the different levels of governance and systemic transitions. It will also ensure that the method is sufficiently flexible for adaptations (Martínez-López et al., 2019b), which is important when comparing perceptions for policy advice across social and geographical aspects of human activities.

\section{DESCRIPTION OF METHODS}

Considering this, the following article presents an example of an adaptive multi-sector implementation of a mix of qualitative and quantitative methodologies. These have allowed us to combine local and scientific knowledge in a collaborative mental mapping framework. We present strengths and weaknesses of the mix of methods and compare results among case studies. The methodology takes into consideration the impacts of decision-making choices and feedback mechanisms on coastal and rural development. It does so by enabling us to interpret participatory conceptual maps and identify problems, to develop practical and robust business road maps and strategic policy recommendations. These are in turn aimed at improving sustainable development and ensure allow implementation grounded in realistic local goals.

\section{Combining Tools}

The process of using a mix of qualitative and quantitative methods to obtain some holistic result is not unproblematic, but it's also no longer unusual and is now an accepted methodological approach. Focusing on creating outcomes that are more generalizable from qualitative approaches can deepen our understanding. It is also very suitable when results need to be useful for interventions and policies (Strijker et al., 2020), as in the case of the current study. We understood that results from approaching social phenomenon around coastal-rural interactions when using both qualitative and quantitative approaches in combination could give us findings that for example: (1) corroborated one other; (2) elaborated on one another, with for example the narratives exemplifying results from the modeling process; (3) complemented each other, in terms of being different but in combination could give more insight into the research question; or (4) contradict one other, with for example stakeholders and expert workshop results conflicting with that of the models (Morgan, 1998; Brannen, 2005).

We prepared for these challenges and potential outcomes while planning for the workshops, among others with building in several steps into the method. These included validation of results from the workshops by smaller inter-sectoral groups. These groups were to consider the interpretations of the research group in the case areas after the initial conceptual modeling exercises. For the workshops, we first used the "Systems Thinking" method (Senge, 1990; Forrester, 1994; Sterman, 2000). System 
thinking uses a stepwise problem-solving approach that allows researchers and practitioners to understand problems from the underlying system feedback structure. This is done by eliciting this information interactively from stakeholders who live and work in the given system, such as fisheries or olive oil industry for example. Systems thinking and systems dynamics exploit transparent, graphical tools that can be used in live sessions to explore real world problems and discuss solutions and obstacles. This process takes the form of group identification of components and processes the participants consider essential. In this case, we focused on the functioning of their given landsea "system." The aim of the research and the stakeholder interactions was to develop an actor-driven representation of this system. These models are graphical visualizations of a basic construct of the system feedback structure, and rely on both qualitative and subjective interpretations of the results from the workshops (Bredehoeft, 2005).

In this study, the conceptual model consisted of components or variables with key relationships between them. These highlighted how the given stakeholders perceived their system, in different socio-geographical regions, including transition pathways toward a desired future state of the system. Understanding the role of system feedback is important for understanding the response of the system to different pressures or management actions, since these can lead to unexpected and counter-intuitive results (Sterman, 2000). The purpose of a conceptual model is two-fold. We can either use it as a research tool for further exploration and quantitative modeling, or as a management tool for consensus building amongst stakeholders. In either case, we can explore future scenarios and actions at local, regional or global levels of governance (Flood, 2010; BeLue et al., 2012). These conceptual models are also known as "concept networks" or "concepts maps" (Axelrod, 2015).

For the purposes of this study, we planned six sectoral workshops in six case areas. The aim of these workshops was to include policy makers, business entrepreneurs, sector representatives, and domain experts to participate in exploring the relevant land-sea interactions from a coastal or rural perspective in each case area. They were encouraged to consider the motivations and barriers for collaboration between regions as well as sectors within their region. They were also asked to consider both positive and negative externalities. We engaged them in an open discussion, using the conceptualization methods from systems thinking. In this process, we identified the main issues, opportunities, obstacles for sustainable development and inter-sectoral synergies in the context of land-sea interaction. To do this, however, and to ensure cross country and sectoral comparison, there was a need for methodological coherence. We therefore started the process by facilitating a workshop with experts from all the six case areas themselves to establish initial drivers of the mental modeling exercise in a flexible and unbiased manner. This method of developing the drivers has been used in a number of studies previously (Tiller et al., 2013, 2016; Salgado et al., 2015; Tiller and Richards, 2015, 2018).

The final list of drivers decided upon by the experts was the following:
1. Water;

2. Human Consumption Pattern;

3. Regulation/Policy;

4. Temperature;

5. Human Migration;

6. Pollution; and

7. Infrastructure.

Water was related to both quality and quantity, saline and fresh according to the experts at this initial workshop-and affected all stakeholders, from urban dwellers to farmers and fishers across case areas. Human consumption pattern was another driver that was considered important, though there were some discussions around the semantics around it. The emphasis was on how the middle class is growing globally, and as such, the demand for more products is increasing as well. Some of the experts felt that the word "Lifestyle" would encompass more, as it would bring in connotations of millennials, smartphones, urbanization, organic food etc. that all are results of changes in human consumption patterns, and simultaneously influence many stakeholder groups. Regulations and policy are natural drivers in any system and there was not much discussion around it. Temperature was another given, though some of the case area experts argued for "climate change" as a variable instead. Human migration was chosen since this is an era in which we see a large movement of people and a lot of challenges associated with this. With human migration, we did not consider only immigration from other nations, but also migration within a nation, often from urban or rural to coastal areas. Pollution was included as well, since many sectors struggle with this, both in terms of being affected by it and being made responsible for it-and as such it was considered an important topic to bring up. Finally, infrastructure was the last driver we considered important enough to reach the "top level" in our mind maps. This also includes a lot, including roads, public transport, airports, internet, canals etc.

\section{Conceptual/Mental Mapping Using VenSim ${ }^{\circledR}$}

The aim of the drivers decided upon in the initial workshop was to use them as conversations starters in participatory workshops where the development of mental models of different stakeholder groups would take place (Figure 1). Several userfriendly software platforms are available for the design, testing and application of these models (Sterman, 2000). Examples are Stella ${ }^{\circledR}$, VenSim ${ }^{\circledR}$, PowerSim ${ }^{\circledR}$, ExtendSim ${ }^{\circledR}$. We decided to use VenSim ${ }^{\circledR}$ for the mental mapping and modeling ${ }^{4}$. This was because of its user-friendliness, and the free license provided. The standard version used is VenSim PLE (Personal Learning Edition), which has the features needed for the mental mapping activities and the SD modeling (Kok and Viaene, 2018). In addition, its functionalities allowed for plug-and-play construction of mental maps by adding variables, issues and the linkages between them.

${ }^{4} \mathrm{~A}$ freeware version of VenSim $\mathbb{R}$ is available online (https://vensim.com/freedownload/). 


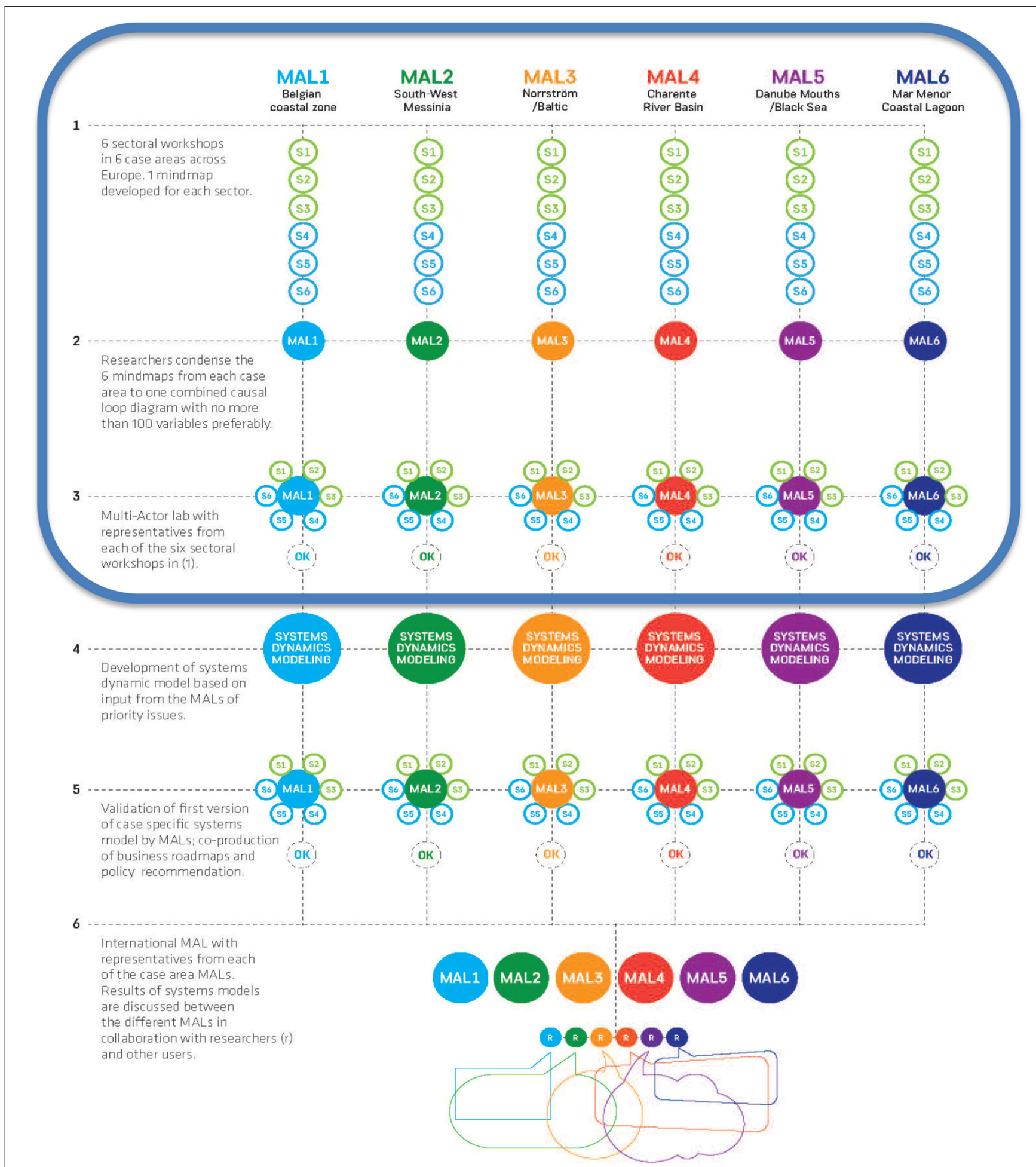

FIGURE 1 | Graphical presentation of the entire stakeholder driven process. This article presents the methodology for the first three parts of the project, which lay the groundwork for possible continuations toward more quantitative models of the work presented here. We had six case areas with six sectoral workshops in each.

\section{Stakeholder Selection}

We selected the groups of stakeholders for the workshops in each of the six case areas using the snowball method (Biernacki and
Waldorf, 1981). Participatory approaches support stakeholder involvement, through which stakeholders can exchange their share experiences, learn about other perspectives. These 
approaches also lets stakeholders examine their perceptions to better understand the behavior of the system (Sterman, 2000). We used this approach because the quality of the results sampled from this group would outweigh the relatively small number of informants the method usually produces, which is often the case in qualitative research studies. In the case of stakeholder workshops, experience had shown us that larger groups can sometimes be ineffective and not provide the detailed and contextual information desired by the researcher. For the purposes of the current study, we therefore considered fifteen participants to be the maximum of what would provide a holistic narrative where all participants were provided ample opportunities to share their perceptions, while allowing for adaptations when necessary. The sample size can be as small as one or two as well, if this participant has information which is of critical value for the given sector and advances the research toward a specific goal (Sandelowski, 1995).

From a natural science and engineering perspective, $n \leq$ 15 participants may seem like a small number of observations. However, samples in qualitative research tend to be smaller than one would expect in the more numerical sciences. This smaller sample aids in supporting the depth of problem driven analysis that is fundamental to the mode of inquiry we use in this study. The samples were also purposive in that they were selected by virtue of the respondent's capacity to provide richly textured information, relevant to the phenomenon under investigation. As such, this purposive sampling (as opposed to probability sampling that is customarily employed in quantitative research) selects "information-rich" cases or respondents. The more useful the data sampled from each of the participant during these sessions, the fewer respondents are needed. In fact, research has shown that after 20 responses, there is seldom any new information to be gained that is analytically relevant in workshops (Green and Thorogood, 2018). The table below (Table 1) specifies how many in total participated in the workshops (rural and coastal each had three workshops).

\section{Sectoral Divided Workshops}

For the first round of workshops, the stakeholders were deliberately divided into the traditional sectors and territories, with three rural and three coastal workshops in each specific case area. The intention was to avoid unnecessary conflicting discussion in this first phase of the project. The facilitator started the group model building experience by presenting pertinent background information about the project and the project aims (Impson, 2011), and informing them of General Data Protection Regulation (GDPR) related to the collection and handling of personal data. The participants were informed that the session would be recorded for purposes of narrative analysis after the workshop and it would be deleted after transcription. After the introduction, each facilitator in each case area asked the stakeholders to consider, from a sectoral perspective, their perceptions on challenges and opportunities around areas of interaction between different sectors in rural and coastal areas. The system conceptualization process was initiated by presenting the participants with the seven predetermined drivers. The facilitator explained that the drivers were variables that could influence other variables, though not always vice versa. They were also described as having multiple "states" or "settings"-for example if the variable is "the color of a boat" then potential states could be red, blue, green etc. The drivers list was purposefully not exhaustive, and the facilitator emphasized that the stakeholders could change them if they did not consider them relevant. They were only to be considered as conversation starters. This ability to change or modify the drivers speaks of the flexibility of this method, since it allows the inclusion of additional drivers through facilitating direct group input or redirection of the discussion when deemed necessary.

The drivers were either be posted on the board with colored "sticky" notes or written on the board directly. The stakeholders were then encouraged to identify the causal interrelationships and connections between these variables in the form of directional associations. This could for example be connections that highlighted that water quality in the olive oil industry (variable "A") was affected by the number of tourists in the area because of pollution (variable " $B$ "). It could also for example be that the amount of fish that an aquaculture company was allowed to have in a pen (variable " $C$ ") directly affected the areas available for fisheries (variable " $D$ "). The result of this stepwise identification of variables and interactions was a system conceptualization or group mental model—or sector mind maps. The process customarily lasted 1 to $2 \mathrm{~h}$; sometimes longer if the stakeholders were very engaged. These maps were graphical representations of the problems, solutions and opportunities and interconnections as perceived by the stakeholders during the sector workshops. The models represented how this particular group of stakeholders collectively viewed the causal pathways between variables at that given time. The model also identified, on closer inspection, where possible solutions and conflict points could be located.

\section{Narrative Analysis}

After the workshops, the research team used the Vensim ${ }^{\circledR}$ software to visualize the results graphically in combination with analyzing the narratives from the workshop thematically, using the diagnostic tools. When needed, the visualization process was coupled with a narrative analysis from the recordings taken during the workshop. Narratives can be described as "discourses with a clear sequential order that connect events in a meaningful way for a definite audience and thus offer insights about the world and/or people's experiences of it" (Hinchman and Hinchman, 1997). To get the narratives from the transcription of the recordings from the workshop, one options is to concoct one's own narrative; that of the researcher's interpretation of what was discussed during the workshop, rewritten from its original form. Another option is to analyze the narratives as special kinds of texts, in and of themselves, using conversation analysis (Czarniawska, 2004). It is also possible to use a combination of the two, interpreting narratives within the context of the workshop setting, and other times treating the text literally as it related to the output of the systems thinking analysis from the workshop. The most important role of a narrative is the knowledge content that can be extracted that might be missed from the model conceptualization process alone 
as relevant element where either ignored or only considered implicitly during the stakeholder exchange. This is in line with Elliott's account of narratives as being instrumental because “... internal validity is ... thought to be improved by the use of narrative because participants are empowered to provide more concrete and specific details about the topics discussed and to use their own vocabulary and conceptual framework to describe life experiences" (2005).

\section{Inter-workshop Interpretations and Development of Causal Loop Diagrams (CLDs)}

We then developed sector specific shared mental maps of the land-sea system in the given case area. The work allowed for further polishing, structuring and correction of the mental map (see point 2 in Figure 1). As a first step, the research teams condensed and simplified the initial mental maps from the sectoral workshops and combined them into one regional mental map of both rural and coastal stakeholders, with $<70$ variables in total. Though this number of variables may still seem large, a result from the first round was that each of the sectoral workshops had in some cases up to 100 variables. As such, this work condensing six workshop mental maps into one causal loop diagram was a time-consuming and intense task that required a lot of patience, expertise, and reflection. To simplify the mental maps and assess the volume of data to be collected, we therefore first prepared poster size printouts of all the initial sector workshop mental maps and put these on the wall for the participants to discuss. This technique was employed to obtain a visualized summary from the initial workshops, and to easily allow an assessment of what variables were discussed by the stakeholders, and which could be combined or discarded (whether as extras or as "opinions" or other reasons). Each workshop was then "restarted" by a facilitator. The case area leaders were asked to discuss each variable on the original map, and were encouraged to combine variables, when possible, and come up with new ones that might better represented a set of variables. The discussion was done in the same order the workshops were originally conducted.

The facilitators also asked the participants who had run the original sectoral workshops to consider data sources, or proxies for data, for each variable they decided to be "keepers" for the later Causal Loop Diagrams (CLDs). The facilitators then had to identify variables that existed in already processed mental maps. This was to ensure that they were not duplicated, but in fact could serve as "links" between the new simplified sectoral models, preparing for joining them all together into a joint CLD. The aim was that each new condensed sectorial model would not have more than 12 variables on average when they are finished processed. While work was ongoing on boards and printouts, simultaneously, another facilitator developed the new Vensim representations graphically, while putting in + (plus) or - (minus) values on the arrows from one variable to the next to represent increasing or decreasing trends in the variables. These were decisions taken by the case area leaders in terms of their recollection of how it was being discussed by the stakeholders in the first workshops. This was to be later validated (or changed) by the stakeholders during the next round of workshops, which were inter-sectoral.

After all the new diagrams had been developed, both on the board and electronically, the latter were combined in the Vensim ${ }^{\circledR}$ software, using the shared variables as links. This was done by cutting and pasting first model two into model one (the new versions) with two different colors. Vensim offers tools to identify identical variables, but we experienced that a manual inspection was necessary. This was because of spelling errors, or similar interpretations of variables that had different words associated with them. At this stage, we then added the key interactions between the sector models as well, with those that link the variables from one to the other. Finally, the teams obtained a full regional model (CLD) of land-sea perceptions and interactions, where all variables ideally could be quantified with existing data or at least through proxies thereof. Figure 2 shows an illustration of the complexities that come out of developing models that include several sectors. The example below is of the land-sea system obtained for the Belgian case area, where six sector workshops were combined (agriculture, environment, spatial planning, fisheries and aquaculture, blue industry and tourism).

\section{Validation of the CLDs in the Multi-Actor Labs}

The case area leaders then further engaged with a representative selection of stakeholders in a multi-actor workshop, where the aim was to validate the CLDs. During this meeting, stakeholder representatives from each of the initial six sectoral workshops were invited to assess the results from not only the sectoral workshops but also the condensation-and CLD development session that had taken place in the meantime. This validation process was done by first presenting the combined CLD (Figure 2 example) and illustrating to the stakeholders how a change in one variable could affect multiple other variables in the system in unexpected ways due to feedback mechanisms. Some multiactor labs used Fuzzy Cognitive Mapping (FCM) to visualize the significance of interactions and analyze the sensitivity of the system for policy interventions. FCMs are weighted, directed graphs which can be used to analyze and visualize system feedback in a semi-quantitative manner. As such this technique finds a place between casual loop diagramming and System Dynamics. The overall aim was to highlight the feedback structure of the system and asking stakeholders if any important links were missing and if the strength of relations was correctly represented. The objective was that the stakeholders would validate the results of the interpretations of the researchers during the inter-workshop session where the CLDs were developed. The number of participants and which sector they represented in each of these workshops is given in Table 2.

\section{DISCUSSION}

The multi-actor labs described above served multiple purposes. The first was as mentioned to validate the outcomes of the coastal and rural sector workshops from a new, synergistic perspective. Secondly, it was to co-produce an integrated, conceptual modela qualitative system model of the land-sea system at the regional 


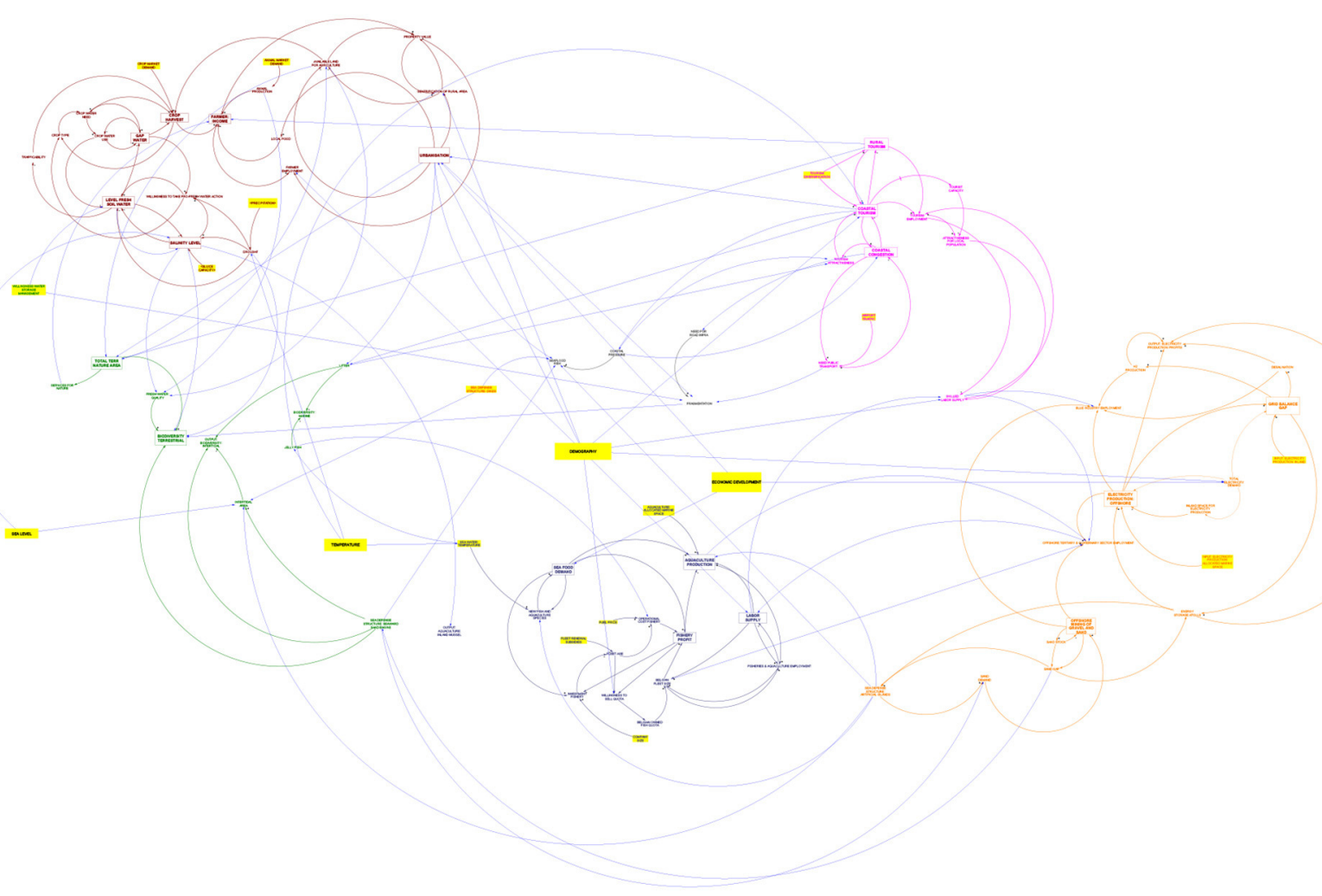

FIGURE 2 | Illustration of how complex a CLD can be after combining six sectoral workshops. The different colors represent the different sectors.

TABLE 1 | Overview of case areas and number of stakeholders in total in the study.

\begin{tabular}{|c|c|c|c|c|}
\hline Country & European sea & Specific case & $\begin{array}{l}\text { Coastal } \\
\text { (3 WSs) }\end{array}$ & $\begin{array}{l}\text { Rural } \\
\text { (3 WSs) }\end{array}$ \\
\hline Greece & $\begin{array}{l}\text { Eastern } \\
\text { Mediterranean } \\
\text { Region }\end{array}$ & South West Messina & 30 & 24 \\
\hline Belgium & Southern North Sea & $\begin{array}{l}\text { Belgian North Sea (BNS); } \\
\text { coastal zone and hinterland } \\
\text { (Province West Flanders) }\end{array}$ & 30 & 29 \\
\hline Sweden & Baltic Sea & Norrström & 31 & 29 \\
\hline Romania & Black Sea & $\begin{array}{l}\text { Danube's Mouths-Black } \\
\text { Sea coast }\end{array}$ & 36 & 61 \\
\hline France & Atlantic region & $\begin{array}{l}\text { Charente River Basin and } \\
\text { Pertuis sea }\end{array}$ & 24 & 30 \\
\hline Spain & $\begin{array}{l}\text { Western } \\
\text { Mediterranean }\end{array}$ & Mar Menor Coastal Lagoon & 35 & 33 \\
\hline
\end{tabular}

Numbers are split between coastal and rural workshops (WSs) and represent the total over three workshops in each case.

scale of the case areas. This could then serve as the architecture for a subsequent evidence-based quantitative system modeling process, and formulation of business road maps and policy guidelines ${ }^{5}$. We also wanted to identify the reinforcing and

${ }^{5}$ This can then serve as architecture for a subsequent evidence-based system modelling process, and formulation of business road maps and policy guidelines. balancing feedback mechanisms underlying the problems and affecting the opportunities for improved land-sea synergy, as reported by the stakeholders. This could then in turn allow us to collectively define and/or validate the significance of the land-sea interactions in the diagram. Finally, we also wanted to challenge the stakeholders to formulate scenarios aimed at regional sustainable development and improved land-sea synergy, taking into consideration potential opportunities and obstacles for implementation.

Contrary to the expectations, none of the inter-sectoral workshops reported problems associated with workshop dialogues when combining sectors. The project teams had anticipated challenges when stakeholders with different and sometimes conflicting objectives (such as agriculture and environmental protection, or aquaculture and fisheries) were brought together to discuss challenges and opportunities around collaborations. Instead, open discussions were reported by all case areas, and the participants appreciated the use of graphical tools and systemic analyses supporting their discussions. The actors attended these workshops to give their opinion on a given situation and their remarks were generally clear and simple because they understood that their contribution could improve the progress of the work. In some cases participants wanted to be sure the researchers had in fact understood the issues so that the project wouldn't produce results that were inadequate or too far from their concerns when it was used as recommendations 
TABLE 2 | Participants multi-actor labs and what sectors they represented in each area.

\begin{tabular}{|c|c|c|c|c|c|}
\hline Mal 1-Greece & Mal 2-Belgium & Mal 3-Sweden & Mal 4-France & Mal 5-Romania & Mal 6-Spain \\
\hline 19 & 18 & 18 & 22 & 24 & 14 \\
\hline Agriculture & Agriculture & Green growth & Agriculture and agro-industry & $\begin{array}{l}\text { Agriculture, cross-compliance } \\
\text { and ecosystem } \\
\text { services }\end{array}$ & Agriculture \\
\hline Tourism & General & Institutions/universities & Tourism & Coastal tourism & Tourism \\
\hline Fishing & Fisheries and aquaculture & Municipalities & Shellfish farming, fisheries & Fisheries and aquaculture & Fisheries and salt pens \\
\hline Local industry & Blue Industry & Blue growth & Ports and infrastructure & $\begin{array}{l}\text { Blue growth-industry, transport } \\
\text { and administration }\end{array}$ & Local population \\
\hline $\begin{array}{l}\text { Administration } \\
\text { and local } \\
\text { authorities }\end{array}$ & Spatial planning & $\begin{array}{l}\text { Administrations/local } \\
\text { authorities }\end{array}$ & Public policies & $\begin{array}{l}\text { Rural development of Danube's } \\
\text { Delta region }\end{array}$ & Administration \\
\hline Institutions/NGOs & Nature & $\begin{array}{l}\text { NGOs and ICT } \\
\text { organizations }\end{array}$ & Water sector & $\begin{array}{l}\text { Rural tourism, recreation and } \\
\text { others rural } \\
\text { activities }\end{array}$ & Environment \\
\hline
\end{tabular}

for policy action or business decisions by managers or decision-makers.

As such, a general lesson from these workshops was to focus on the practical implications of the analyses with scenarios rather than methodological technicalities. This practical approach was stated with reference to the presentations of the interactive design and polishing and improvement of the merged CLDs for the land-sea system. However, one of the concerns in analyzing the outcomes of such a participatory and systems thinking approach was how detailed a CLD should be to properly reflect system behavior. Including more elements and connections might make the conceptual representation more realistic or instead more inert. Moreover, stakeholders expressed a clear demand to continue getting informed on the modeling process and to provide again their expert opinion on the various outcomes of the modeling exercise, i.e., policy measures, financial perspectives, and future benefits, among others.

We did identify differences between the MALs and interpretation of the guidelines for implementation that we decided upon at the start of the project when the drivers were developed. These pertain to differences in the complexity and thematic focus of the MALs, the presentation and the level of detail used in the diagrams, and the level of detail of the narrative scenarios. This, however, speaks to the flexibility and adaptability of this method and is one of its benefits. Results showed in the end that there is considerable overlap in the issues affecting coastal-rural interaction in the six different case-areas (Table 3).

The general impact of the results from the workshops, and the analysis of the policy relevant themes in the six case areas were for example that there was great variability in the importance of themes between regions, but some themes are important in all countries. CAP themes, however, are generally found important everywhere, while the importance of marine strategic directive themes varies between case areas.

\section{CONCLUSION}

The main challenges of the methodology we chose is in its inherent complicated nature. It involves numerous stakeholder groups from different and often competing sectors, which in addition is layered with different geographical areas around Europe also include the element of both the rural and the coastal areas. In addition, the stakeholder integration process itself is difficult at best. Reaching stakeholders and ensuring that there was adequate-but not too high-attendance at the workshops was also difficult. We used the snowball method and gatekeepers, which helped in this endeavor. This targeted approach ensured that rather than high numbers, we had the correct stakeholders with the correct background and interest in the topic attending. It did however require a lot of effort in ensuring participation.

Stakeholder fatigue was another challenge we were faced with. Most of the stakeholders had a great interest in the topic, and were generally approachable, and as such were invited to attend multiple different research projects and workshops and were susceptible to being "overused" in research projects. Furthermore, many participants expected there to be more immediate results that would show direct relevance to their field, which is not always the case in research projects, where results take time. Even after detailed briefings, there also seemed to be a general lack of understanding of the way a research project works and the time that is needed to move from qualitative data collection to a good synthesis of the results and subsequent quantitative modeling. As such, ensuring good communication and making sure that stakeholders are continuously kept in the loop on ongoing developments of the project and results was determined to be critical to ensure continuous participation. This has been solved differently in all the different case areas, and this is also a methodological choice. It was also our perception that keeping stakeholder engaged and interested and continuously coming to workshops was more difficult in urban environments than in rural ones. We speculate that this could be because of a lack of community feeling in these areas, and therefore also 
TABLE 3 | The themes in column 1 of the table are first themes we extracted based on the deliverable itself and the workshops in the six case areas.

\begin{tabular}{|c|c|c|c|c|c|c|}
\hline & Belgian coastal zone & Messina & Baltic & Charente & Danube Mouth & Mar Menor \\
\hline Inland water quality & 2 & 2 & 2 & 2 & 2 & 2 \\
\hline Fresh water availability & 2 & 2 & 0 & 2 & 1 & 2 \\
\hline Rural economy reform & 1 & 2 & 1 & 2 & 2 & 2 \\
\hline Funding for agriculture transition & 0 & 2 & 0 & 1 & 2 & 1 \\
\hline Rural gentrification & 2 & 0 & 0 & 2 & 0 & 2 \\
\hline (On land) spatial planning & 2 & 2 & 2 & 2 & 1 & 2 \\
\hline Management of nature areas & 0 & 2 & 0 & 1 & 2 & 2 \\
\hline Capacity building & 1 & 2 & 2 & 0 & 2 & 1 \\
\hline Bureaucracy & 0 & 2 & 0 & 1 & 2 & 2 \\
\hline Preserve local traditions & 1 & 1 & 0 & 0 & 2 & 1 \\
\hline Tourism coordination & 2 & 2 & 2 & 0 & 2 & 2 \\
\hline Tourism diversification & 2 & 2 & 0 & 1 & 2 & 2 \\
\hline International cooperation & 2 & 0 & 2 & 0 & 2 & 0 \\
\hline Cross-sector cooperation & 2 & 2 & 2 & 2 & 2 & 2 \\
\hline Coastal water quality & 1 & 2 & 2 & 2 & 2 & 2 \\
\hline Marine spatial planning & 2 & 2 & 1 & 1 & 2 & 1 \\
\hline Climate change and sea defense & 2 & 2 & 1 & 1 & 1 & 1 \\
\hline Aquaculture regulation & 2 & 2 & 1 & 2 & 2 & 0 \\
\hline \multicolumn{7}{|l|}{ COMMON AGRICULTURE POLICY POINTS } \\
\hline Ensuring viable farm income & 2 & 2 & 0 & 2 & 2 & 1 \\
\hline Increasing competitiveness & 2 & 2 & 1 & 1 & 1 & 1 \\
\hline Farmer position in value chains & 2 & 2 & 0 & 2 & 2 & 0 \\
\hline Agriculture and climate mitigation & 2 & 2 & 1 & 2 & 1 & 0 \\
\hline Efficient soil management & 0 & 2 & 1 & 1 & 2 & 2 \\
\hline Biodiversity and farmed landscapes & 1 & 2 & 1 & 2 & 2 & 1 \\
\hline Structural change and generational re & 1 & 2 & 0 & 1 & 1 & 0 \\
\hline Jobs and growth in rural areas & 1 & 2 & 1 & 2 & 2 & 2 \\
\hline Health, food and antimicrobial resistance & 0 & 2 & 1 & 1 & 1 & 0 \\
\hline Simplifying the CAP & 0 & 2 & 1 & 0 & 0 & 0 \\
\hline \multicolumn{7}{|c|}{ MARINE STRATEGIC FRAMEWORK DIRECTIVE DESCRIPTORS } \\
\hline Biological diversity & 2 & 1 & 0 & 2 & 2 & 2 \\
\hline Non-indigenous species & 1 & 1 & 0 & 1 & 1 & 1 \\
\hline Commercially exploited fish and shellfish & 2 & 2 & 0 & 1 & 2 & 2 \\
\hline Marine food webs & 1 & 0 & 0 & 1 & 0 & 1 \\
\hline Eutrophication & 1 & 1 & 2 & 1 & 2 & 2 \\
\hline Sea-floor integrity & 2 & 2 & 0 & 1 & 1 & 0 \\
\hline Hydrographical conditions & 0 & 0 & 0 & 1 & 1 & 2 \\
\hline Contaminants & 0 & 2 & 2 & 2 & 1 & 2 \\
\hline Contaminants in fish and other seafood & 0 & 1 & 0 & 2 & 2 & 2 \\
\hline Marine litter & 2 & 2 & 0 & 1 & 1 & 2 \\
\hline Underwater noise and other forms of pollution & 1 & 0 & 0 & 0 & 0 & 1 \\
\hline
\end{tabular}

Then we related these to the Common Agricultural Policy (CAP) and the Marine Strategic Framework Directive (MSFD) and added weights of importance to these as well.

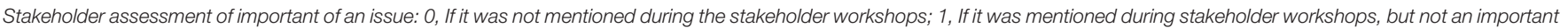
issue; 2, If they found that it was an important issue during the stakeholder workshops.

a lack in interest in other sectors. We also hypothesize that it could be because of the larger number of planning and decisionmaking project that are inherent to such urban areas (compared to rural), which make participants more critical to new initiatives and therefore also more in demand. This is however something that should be considered in future work using this methodology.

This returns us to the discussions of how different methods in the same study come together in the end-in terms of whether they corroborate, elaborate, complement, or contradict each other. So far in the process, they have complemented each other in that the workshops have provided more depth and new insights into traditional modeling and allowed for the inclusion of new variables, interactions, data, and considerations that were not expected before the start of the study. Invariably, however, some issues may become contradictory in that workshop mind maps sometimes reflect wishes and perceptions rather than facts. 
In addition, we need to acknowledge the challenge of granularity. Participants sometimes tend to lose track of the big picture and add more detail to parts of the model they know best and have a personal interest in-when more depth and new sights are no longer practical for the modeling purposes. This was especially the case for people representing particular interest, who always kept emphasizing their particular interest (which is often a very small issue that doesn't really influence the big picture/system). Finding an equilibrium between on the one hand trying to keep the interest of stakeholders and focusing on their specific problems - and on the other hand keeping a focus on the holistic system and intersectoral interactions is very difficult.

This study has allowed us, though, to start the participatory modeling of key scenarios for modeling purposed, developed by the stakeholders themselves and agreed upon across coastalrural areas in Europe. This can be applied to assess the effect of different management practices on several socio-ecological indicators and ensure the deep integration of stakeholders for increased legitimacy and compliance with resultant policy action plans and regulations. The challenge for the workshops is now to convert the outcomes of the multi-actor analyses evidence based CLD into quantitative models using system dynamics, while keeping in consideration the priorities of the stakeholders and conclusions of the multi-actor workshops-and avoiding more details while still retaining stakeholder interest.

\section{DATA AVAILABILITY STATEMENT}

The raw data supporting the conclusions of this article will be made available by the authors, without undue reservation.

\section{REFERENCES}

Axelrod, R. (2015). Structure of Decision: The Cognitive Maps of Political Elites. Princeton, NJ, Princeton University Press. doi: 10.1515/9781400871957

BeLue, R., Carmack, C., Myers, K. R., Weinreb-Welch, L., and Lengerich, E. J. (2012). Systems thinking tools as applied to community-based participatory research: a case study. Health Educ. Behav. 39, 745-751. doi: 10.1177/1090198111430708

Biernacki, P., and Waldorf, D. (1981). Snowball sampling: problems and techniques of chain referral sampling. Sociol. Methods Res. 10, 141-163. doi: 10.1177/004912418101000205

Bouhnik, D., and Giat, Y. (2015). Information gatekeepers-Aren't we all. Inform. Sci. Int. J. Emerg. Trans. 18, 127-144. doi: 10.28945/2270

Brannen, J. (2005). Mixing methods: the entry of qualitative and quantitative approaches into the research process. Int. J. Soc. Res. Methodol. 8, 173-184. doi: 10.1080/13645570500154642

Bredehoeft, J. (2005). The conceptualization model problem-surprise. Hydrogeol. J. 13, 37-46. doi: 10.1007/s10040-004-0430-5

Bruckmeier, K., and Höj Larsen, C. (2008). Swedish coastal fisheries-From conflict mitigation to participatory management. Mar. Policy 32, 201-211. doi: 10.1016/j.marpol.2007.09.005

Clark, J. R. (1994). Integrated Management of Coastal Zones: FAO Fisheries Technical Paper 327. University of Miami.

Coleman, E. A., Manyindo, J., Parker, A. R., and Schultz, B. (2019). Stakeholder engagement increases transparency, satisfaction, and civic action. Proc. Nat. Acad. Sci. U.S.A 116, 24486-24491. doi: 10.1073/pnas.190843 3116

Cottrell, R. S., Fleming, A., Fulton, E. A., Nash, K. L., Watson, R. A., and Blanchard, J. L. (2018). Considering land-sea interactions and trade-offs for food and biodiversity. Glob. Chang. Biol. 24, 580-596. doi: 10.1111/gcb.13873

\section{ETHICS STATEMENT}

The studies involving human participants were reviewed and approved by NSD-Norwegian Center for Research Data. The patients/participants provided their written informed consent to participate in this study.

\section{AUTHOR CONTRIBUTIONS}

RT came up with the concept, organized the paper, did the theoretical framework, the introduction and the conclusion, and the sewing together of the work done in the case areas. GD, ZK, and SS-A were responsible for holding the stakeholder workshops in the Swedish case area and for collating the information from these for the article. MG, LL, FT, BN, and J-LK were responsible for holding the stakeholder workshops in the Romanian case area and for collating the information for the article. EK and GM were responsible for holding the stakeholder workshops in the Greek case area and for collating the information for the article. J-ML and FV were responsible for holding the stakeholder workshops in the French case area and for collating the information for the article. JM-L and JV were responsible for holding the stakeholder workshops in the Spanish case area and for collating the information for the article.

\section{ACKNOWLEDGMENTS}

The authors would like to acknowledge funding from the European Union's Horizon 2020 Research and Innovation programme under Grant Agreement $N^{\circ} 773782$.

Czarniawska, B. (2004). Narratives in Social Science Research. London: Sage. doi: 10.4135/9781849209502

De Vente, J., Reed, M. S., Stringer, L. C., Valente, S., and Newig, J. (2016). How does the context and design of participatory decision making processes affect their outcomes? Evidence from sustainable land management in global drylands. Ecol. Soc. 21:24. doi: 10.5751/ES-08053-210224

Elliott, J. (2005). Using Narrative in Social Research: Qualitative and Quantitative Approaches. London: Sage.

Estellie Smith, M. (1995). The nature of Nature: conflict and consensus in fisheries management. Aquat. Living Resour. 8, 209-213. doi: 10.1051/alr:19 95020

European Commission (2006). Council Decision of 20 February 2006 on Community Strategic Guidelines for Rural Development (Programming Period 2007 to 2013). Available online at: 2006/144/EC. https://eur-lex.europa.eu/ legal-content/EN/ALL/?uri=CELEX:32006D0144 (accessed March 26, 2020).

European Commission (2019a). Fitness Check of the Water Framework Directive and the Floods Directive. Available online at: https://ec.europa.eu/ environment/water/fitness_check_of_the_eu_water_legislation/documents/ Water\%20Fitness\%20Check\%20-\%20SWD(2019)439\%20-\%20web.pdf (accessed March 26, 2020).

European Commission (2019b). How big is the EU's Blue Economy? The EU Report on Potential of Coasts and Oceans to Provide for Sustainable Economic Growth Published. Available online at: https://ec.europa.eu/jrc/en/news/how-big-eusblue-economy-eu-report-potential-coasts-and-oceans-provide-sustainableeconomic-growth (accessed March 26, 2020).

European Environment Agency (2016). Coasts and Seas. Available online at: https://www.eea.europa.eu/themes/coast_sea/intro (accessed March 26, 2020).

Eurostat (2018). Urban and Rural Living in the EU. Available online at: https:// ec.europa.eu/eurostat/web/products- eurostat-news/-/EDN-20200207- 1 (accessed March 26, 2020). 
Flood, R. (2010). The relationship of "systems thinking" to action research. Syst. Pract. Action Res. 23, 269-284. doi: 10.1007/s11213-010-9169-1

Forrester, J. W. (1994). System dynamics, systems thinking, and soft OR. Syst. Dyn. Rev. 10, 245-256. doi: 10.1002/sdr.4260100211

Green, J., and Thorogood, N. (2018). Qualitative Methods for Health Research. London: Sage.

Haas, P. M. (1989). Do regimes matter? Epistemic communities and Mediterranean pollution control. Int. Organ. 43, 377-403. doi: $10.1017 /$ S0020818300032975

Herrera, V. (2019). Reconciling global aspirations and local realities: challenges facing the Sustainable Development Goals for water and sanitation. World Dev. 118, 106-117. doi: 10.1016/j.worlddev.2019.02.009

Hinchman, L. P., and Hinchman, S. (1997). Memory, Identity, Community: The Idea of Narrative in the Human Sciences. Albany, NY, Suny Press.

Impson, S. (2011). The blue food revolution. Sci. Am. 304, 54-61. doi: 10.1038/scientificamerican0211-54

Kamau, M., Chasek, P., and O'Connor, D. (2018). Transforming Multilateral Diplomacy: The Inside Story of the Sustainable Development Goals. Oxfordshire: Routledge. doi: 10.4324/9780429491276

Kelle, U. (2006). Combining qualitative and quantitative methods in research practice: purposes and advantages. Qual. Res. Psychol. 3, 293-311. doi: $10.1177 / 1478088706070839$

Kok, J.-L. D., and Viaene, P. (2018). COASTAL Deliverable D12-Model Scope and Feedback Structure. European Union's Horizon 2020 Research and Innovation Programme Under Grant Agreement 773782.

Langhans, S. D., Domisch, S., Balbi, S., Delacámara, G., Hermoso, V., Kuemmerlen, M., et al. (2019). Combining eight research areas to foster the uptake of ecosystem-based management in fresh waters. Aquat. Conserv. Mar. Freshw. Ecosyst. 29, 1161-1173. doi: 10.1002/aqc.3012

Lewin, K. (1943). Forces Behind Food Habits and Methods of Change, From: Guthe, C. and Mead, M. The problem of Changing Food Habits, Report of the Committee on Food Habits. Bulletin of the National Research Council.

Leys, A., and Vanclay, J. (2011). Stakeholder engagement in social learning to resolve controversies over land-use change to plantation forestry. Reg. Environ. Change 11, 175-190. doi: 10.1007/s10113-010-0132-6

Martínez-López, J., Bergillos, R. J., Bonet, F. J., and de Vente, J. (2019a). Connecting research infrastructures, scientific and sectorial networks to support integrated management of Mediterranean coastal and rural areas. Environ. Res. Lett. 14:115001. doi: 10.1088/1748-9326/ab4b22

Martínez-López, J., Teixeira, H., Morgado, M., Almagro, M., Sousa, A. I., Villa, F., et al. (2019b). Participatory coastal management through elicitation of ecosystem service preferences and modelling driven by "coastal squeeze." Sci. Total Environ. 652, 1113-1128. doi: 10.1016/j.scitotenv.2018.10.309

Mielke, J., Vermaßen, H., and Ellenbeck, S. (2017). Ideals, practices, and future prospects of stakeholder involvement in sustainability science. Proc. Nat. Acad. Sci. U.S.A. 114, 10648-10657. doi: 10.1073/pnas.1706085114

Morgan, D. L. (1998). Practical strategies for combining qualitative and quantitative methods: applications to health research. Qual. Health Res. 8, 362-376. doi: 10.1177/104973239800800307

Reed, M. S. (2008). Stakeholder participation for environmental management: a literature review. Biol. Conserv. 141, 2417-2431. doi: 10.1016/j.biocon.2008.07.014

Salgado, H., Bailey, J., Tiller, R., and Ellis, J. (2015). Stakeholder perceptions of the impacts from salmon aquaculture in the Chilean Patagonia. Ocean Coast. Manag. 118, 189-204. doi: 10.1016/j.ocecoaman.2015.07.016

Sandelowski, M. (1995). Sample size in qualitative research. Res. Nurs. Health 18 , 179-183. doi: 10.1002/nur.4770180211

Senge, P. M. (1990). The Fifth Discipline: The Art and Practice of the Learning Organization. New York, NY: Doubleday.
Smith, C. L. (1980). Management provoked conflict in fisheries. Environ. Manag. 4, 7-11. doi: 10.1007/BF01866215

Sterman, J. (2000). Business Dynamics: Systems Thinking and Modelling for a Complex World. Boston, MA: McGraw Hill Higher Education.

Stock, P., and Burton, R. J. (2011). Defining terms for integrated (multiinter-trans-disciplinary) sustainability research. Sustainability 3, 1090-1113. doi: $10.3390 /$ su3081090

Strijker, D., Bosworth, G., and Bouter, G. (2020). Research methods in rural studies: qualitative, quantitative and mixed methods. J. Rural Stud. 78, 262-270. doi: $10.1016 /$ j.jrurstud.2020.06.007

Sun, Y. (2017). transnational public-private partnerships as learning facilitators: global governance of mercury. Glob. Environ. Politics 17, 21-44. doi: 10.1162/GLEP_a_00399

The World Bank (2018). Rural Population (\% of Total Population). Available online at: https://data.worldbank.org/indicator/SP.RUR.TOTL.ZS (accessed March $26,2020)$.

Tiller, R., De Kok, J.-L., Vermeiren, K., Richards, R., Ardelan, M. V., and Bailey, J. (2016). Stakeholder perceptions of links between environmental changes to their socio-ecological system and their adaptive capacity in the region of Troms, Norway. Front. Mar. Sci. 3:267. doi: 10.3389/fmars.2016.00267

Tiller, R., Gentry, R., and Richards, R. (2013). Stakeholder driven future scenarios as an element of interdisciplinary management tools; the case of future offshore aquaculture development and the potential effects on fishermen in Santa Barbara, California. Ocean Coast. Manag. 73, 127-135. doi: 10.1016/j.ocecoaman.2012.12.011

Tiller, R., and Richards, R. (2015). Once bitten, twice shy: aquaculture, stakeholder adaptive capacity, and policy implications of iterative stakeholder workshops; the case of Frøya, Norway. Ocean Coast. Manag. 118(Pt B), 98-109. doi: 10.1016/j.ocecoaman.2015.09.001

Tiller, R., and Richards, R. (2018). Ocean futures: exploring stakeholders perceptions of adaptive capacity to changing marine environments in Northern Norway. Mar. Policy. 95, 227-238. doi: 10.1016/j.marpol.2018.04.001

United Nations (2015). Sustainable Development Goal 14: Targets and Indicators. Available online at: https://sustainabledevelopment.un.org/sdg14 (accessed March 26, 2020).

United Nations (2017). Factsheet: People and Oceans. The Ocean Conference: United Nations, New York. Available online at: https://www.un.org/ sustainabledevelopment/wp-content/uploads/2017/05/Ocean-fact-sheetpackage.pdf (accessed March 26, 2020).

Conflict of Interest: The authors declare that the research was conducted in the absence of any commercial or financial relationships that could be construed as a potential conflict of interest.

Publisher's Note: All claims expressed in this article are solely those of the authors and do not necessarily represent those of their affiliated organizations, or those of the publisher, the editors and the reviewers. Any product that may be evaluated in this article, or claim that may be made by its manufacturer, is not guaranteed or endorsed by the publisher.

Copyright (C) 2021 Tiller, Destouni, Golumbeanu, Kalantari, Kastanidi, Lazar, Lescot, Maneas, Martínez-López, Notebaert, Seifollahi-Aghmiuni, Timofte, de Vente, Vernier and de Kok. This is an open-access article distributed under the terms of the Creative Commons Attribution License (CC BY). The use, distribution or reproduction in other forums is permitted, provided the original author(s) and the copyright owner(s) are credited and that the original publication in this journal is cited, in accordance with accepted academic practice. No use, distribution or reproduction is permitted which does not comply with these terms. 